\title{
Abstract \\ Child Poverty and Household Coping Strategies in Croatia: A Quantitative-Qualitative Study
}

\author{
RESEARCH ARTICLE \\ Ivica Rubil* \\ Paul Stubbs** \\ Siniša Zrinščak ${ }^{* * *}$
}

Official poverty statistics, including child poverty statistics, based on the risk-ofpoverty rate, is silent about how the poor really live and which coping strategies they use. To take that into account, one should start "from the bottom", from the poor themselves, and gather information on actual hardships the poor face, using appropriate research instruments. This paper is focused on child poverty in Croatia, and attempts to gain insights into the coping strategies of households with children. The analysis consists of: a quantitative part based on a survey of parents and children from 207 households with school-age children that are beneficiaries of the guaranteed minimum benefit; and a qualitative part based on focus groups and semi-structured individual interviews with 20 previously surveyed parents. The results of both parts, which mostly confirm the existing findings, point to very adverse living conditions of poor households with children, which they try to cope with using various coping strategies, including borrowing, work in the shadow economy, asking others for help, prioritization in consumption, and the like. The findings also suggest that there are certain differences in the living conditions, coping strategies, and the poverty impact upon children, depending on the depth of poverty, settlement size and parents' education. Especially worrying is the parents' inability to afford for their children goods and services needed for them to be fully socially included, as well as education that would ensure them an upward social mobility.

Keywords: poverty, children, school age, coping strategies, guaranteed minimum benefit, survey, focus groups, interview, Croatia

JEL classification: I2, J1

\footnotetext{
* Ivica Rubil, postdoctoral researcher, The Institute of Economics, Zagreb, e-mail:irubil@eizg.hr.

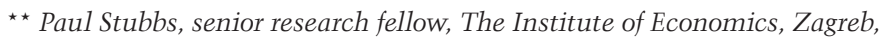
e-mail:pstubbs@eizg.hr.

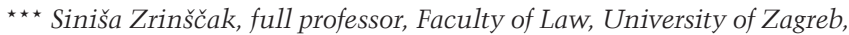
e-mail: sinisa.zrinscak@pravo.hr.
} 